\title{
Correction to: Wavefront and Coherence Characteristics \\ of Extreme UV and Soft X-ray Sources
}

\author{
Bernd Schäfer, Bernhard Flöter, Tobias Mey, and Klaus Mann
}

\section{Correction to:}

Chapter 20 in: T. Salditt et al. (eds.), Nanoscale Photonic

Imaging, Topics in Applied Physics 134,

https://doi.org/10.1007/978-3-030-34413-9_20

The book was inadvertently published with the error in the reference section of chapter 20. The correction detail is as follows:

[14] Ruiz-Lopez, M.: Wavefront propagation simulations supporting the design of a time delay compensating monochromator beamline at flash2 (2018)

Photon Diag. 2018needs to be replaced by:

[14] Private communication Barbara Keitel and Elke Plönjes (DESY), to bepublished in detail elsewhere

The chapter and book has been updated with the change.

The updated version of this chapter can be found at

https://doi.org/10.1007/978-3-030-34413-9_20 